\title{
A ARTE DA ILUMINAÇÃO
}

Fernando Carlos Chamas

Resumo: Quando o Buda histórico, Siddharta Gautama, passou a ser representado em esculturas e pinturas, tentou-se expressar as 32 características corporais dos seres que já atingiram a iluminação, os Budas da categoria Nyorai.

Palavras-chave: Buda, 32 sinais corporais, escultura budista, Japão.

Abstract: When the historical Buddha, Siddharta Gautama, passed to be represented in sculptures and paintings, the artists tried to express the 32 corporal characteristics of the beings that already had reached the illumination, the Buddhas of the Nyorai category.

Key-words: Buddha, 32 signals, Buddhist sculpture, Japan.

A palavra sânscrita buddha não é um nome pessoal, embora seja também usada como um louvor às pessoas consideradas sagradas ou dignas pela sabedoria que possuem. Sendo a flexão de buddh no particípio passado do sânscrito e significando "desperto" tem o caráter diferente de uma pessoa santa, termo mais relacionado às boas ações, castidade, devoção e milagres antes e depois da morte do santo. O "desperto" passou por um processo de transformação, ou seja, supõe-se que não nasceu santo, mas cheio de dúvidas e perturbações metaforizadas pela escuridão. $\mathrm{O}$ processo se chamou de "iluminação" e buda passou a significar "o ser iluminado", ou seja, em contraste, há também uma relação metafórica entre luz e sabedoria nas mesmas proporções. Em japonês, usamos o ideograma go (悟) e sua forma verbal satoru (悟る) 
em diversas combinações para designar vários processos ou estados de perfeição. Devemos compreender que o "estado de perfeição" é a capacidade de se manter no processo, ou seja, um caminho progressivo e dinâmico de iluminação (godô, 悟道) e não um fim ou objetivo a ser atingido e mantido para sempre, o que auto-violaria o conceito budista de temporalidade. Aquele que iniciou esse caminho fez o gonyû (悟入) como conseqüência do seu "estado iluminado" (jap., satottamono 悟った者, e inglês, buddhahood) " Outro termo é kenshô (見性), que significa olhar para dentro de nossa própria natureza e dominá-la pela compreensão (jibun-no shinsei-wo mitoosu koto, 自分の心性を見通すこと) e assim atingir a iluminação (kenshôjôbutsu, 見性成仏) e tornar-se um kenshôsha (見性者). Portanto, o estado iluminado resulta de uma predisposição constante para a observação interior sem a pretensão de uma consciência total de si mesmo, mas uma sensibilidade peculiar de ser, ao máximo, consciente das próprias ações, como prega os oito passos budistas ${ }^{1}$. Nesse sentido, Buda representa o observador arquetípico primordial capaz de ver a verdadeira forma das coisas e mantêlo desperto é o estado iluminado. Há outros sinônimos para Buda. É também chamado kakusha (覚者, “o iluminado”) e chisha (知者, “o sábio”). Embora muitos ideogramas tenham sido usados apenas foneticamente para transcrever nomes próprios budistas, o epíteto sânscrito Tathagata sofreu uma interpretação. Tatha é a "condição original" e gata é "indo ou vindo", portanto "sempre próximo dos seres e apenas mais um dos próximos budas" Em nyoko (如去), Buda está indo para o mundo da verdade. Em nyorai (如来), Buda está vindo para o nosso mundo. Os japoneses e os chineses dão maior ênfase ao "vindo"

Enfim, nyorai é um dos dez epítetos (jûgô, 十號) de Buda, a saber:

1. Nyorai (如来), “aquele que veio do mundo da verdade";

2. Arakan (阿羅漢), “aquele que merece oferendas”;

3. Shôbenchi (正遍智), "aquele que conhece tudo perfeitamente";

4. Myôgyô-soku (明行足), “aquele que vê a verdade e anda pelo caminho satisfatoriamente";

5. Zenzei (善逝), "aquele que está no mundo da iluminação";

6. Sekenge (世間解), “aquele que entende o mundo";

7. Mujôji (無上士), “o incomparável";

8. Jôgo-jôbu (調御丈夫), “aquele que controla os homens";

9. Tenninshi (天人師), "aquele que ensina deuses e homens";

10. Butsu-seson (仏世尊), “o iluminado que é honrado pelas pessoas do mundo".

1. Para cessar o sofrimento, o homem inteligente deve submeter sua vontade ao dever e seguir a senda óctupla: reta compreensão, reto propósito, reta palavra, reta conduta, retos meios de subsistência, reto esforço, reta atenção e reta meditação.

2. JAPANESE-English Buddhist Dictionary ("Dicionário de Termos Budista em Japonês-Inglês"). Tôkyô: Daitô Shuppansha, 1965. 
Esses epítetos evocam qualidades abstratas de grande magnificência, mas ainda não nos dão informações suficientes para fazer uma estátua de Buda. Até então, sua grandeza espiritual poderia se refletir numa grandeza fisica, com imagens gigantescas esculpidas nas paredes dos penhascos, e sua fisionomia deveria exprimir a característica essencial do budismo mahayana, uma compaixão sem limites, e uma serenidade inefável só possível àqueles que estão iluminados pela suprema sabedoria. Com o correr dos séculos, das lendas e das culturas por onde passou o budismo, após a sua morte, Buda foi considerado como um super-humano e sua representação pictórica tinha características não humanas. Também podemos supor uma apreciação de características físicas mitologicamente relacionadas aos deuses locais, dos quais os líderes acreditavam descender. Tais características extraordinárias foram sendo somadas, $o$ que resultou em sôgô (相好) ou laksana-vyañjana que aponta trinta e duas características corporais e oitenta marcas secundárias, shugô (種好). Laksana são as fáceis de serem vistas e vyañjana são as dificeis, de qualquer forma jamais encontradas em seres humanos comuns. Os oitenta sinais são tidos como favoráveis e então chamados de (hachijisshugô, 八十種好 ou hachijûzuigyôgô, 八十隋形好), uma versão mais detalhadas dos trinta e dois, como o modo de andar largo e amplo como de um elefante $\mathrm{e}$ as orelhas caídas longamente na orbicular, etc. O bigode pode ser aqui incluído. Tais marcas identificariam um ser humano ideal, um super-humano. Sanjûni-sô (三十二相) é como se refere aos "trinta e dois sinais" característicos sobre o corpo de Buda ${ }^{3}$ : As primeiras características herdadas dos imensos budas esculpidos nas montanhas devem ser as (19) Jôshinshishisô (上身獅子相), onde a metade superior do corpo é majestosa, serena e solene "como a do leão shishi"4; a (20) Daichokushinsô (大直身相), que fala de um corpo vasto, de retidão e postura ímpares, e (21) Ken'enkôsô (肩円好相) com ombros cheios e de forma majestosa.

No (01) Sokka anbeiritsusô (足下安平立相): as solas dos pés são chatas supondo-se uma total aderência ao solo quando a imagem está ereta. Quando em postura de lótus (kekkafuza, 結跏跃座), com o peito do pé sobre a coxa oposta, essa característica é mais notável, sendo que as linhas naturais da sola dos pés são substituídas pelos desenhos esotéricos budistas, mais exatamente o (02) Sokkasenpukurinsô (足下千福輪相) ou sokkanirinsô (足下二輪相), o sinal senpukurin (千福輪). Isto é o Dharma-cakra ou Hôrin ou Senpukurin (Roda de Mil Raios), a Roda do Dharma ou da Lei, uma metáfora dos ensinamentos que esmagam os inimigos em seu caminho e estão em movimento incessante. Foi este principal sinal que o sábio Asita viu no corpo

3. Essa compilação baseia-se nos dicionários: JAPANESE-English Buddhist Dictionary. Tôkyô: Daitô Shuppansha, 1965 / SAWA, Ryûten (comp.). Butsuzôzuten. Tôkyô: Yoshikawa Kôbunkan, 1972. / A DICTIONARY of Japanese Art Terms. Tôkyô Bijutsu, 1990. Seguem-se as numerações originais dispostas em parágrafos de interpretação.

4. Shishi ou Jishi é traduzido como leão, mas também pode ser um cervo ou um cão mágico e tem o poder de repelir os maus espíritos. 
de Buda quando ele nasceu, prevendo que Buda seria um grande rei ou um grande sábio. Essa simples passagem confirma um conhecimento pré-Buda Gautama e ancestral de "sinais auspiciosos" (kissô, 吉相).

Algumas características confundem ainda mais os historiadores no sentido que às vezes é muito dificil distinguir se uma característica é um estilo de um período ou se já é uma característica própria de estilo diferente como o (03) Chôshisô (長指相) com os dedos das mãos e dos pés compridos e delgados. Dentre todas as características, essas são as que mais impressionam, pois dedos muito longos e às vezes com longas unhas, mais se parecem com garras ameaçadoras, mas que certamente também pode ser um requisito de beleza indispensável em algum ponto de vista estético que viu suavidade nesse modo de representar os pés e as mãos, o (6) Shusokunyunansô (手足柔軟相). Perdeu-se no tempo uma reposta para a necessidade das membranas entre os dedos (mizukaki, 蹼 ou 水择き) das mãos e dos pés (05) Shusokushimanmôsô (手足指漫網相). Embora possam sugerir que Buda deseje salvar as pessoas com as mãos largamente abertas, também sugere um legado de imaturidade da habilidade dos artistas indianos durante o estágio de formação da arte de fazer imagens. Em outras palavras, os primeiros escultores indianos não teriam sido capazes de representar dedos individuais. De qualquer forma, o padrão delgado se reflete em (08) Rokuôenshitsususô (鹿王延膝相) ou Inienshitsusô (伊尼延膝相) com pernas esbeltas e joelhos pequenos "como os de um gamo" (inien) e (09) Shôrisshumashissô (正立手摩膝相) com braços tão compridos que, em pé, as mãos quase tocam os joelhos. Isso dá uma sensação de ausência da gravidade, ou de leveza serena e elegante, mais uma vez insistida em (17) Nanashôryûmansô (七好隆満相), onde mãos, pés, ombros, nuca e músculos são delicados e suaves, nas mesmas proporções. Até aqui pode-se notar uma preocupação matemática para a representação dessa expressão figurativa de "perfeição completa" (kanzen-muketsu, 完全無欠), somando-se o (11) Shinkôchôtôsô (身広長等相) com os comprimentos da altura total e da distância entre os braços abertos são iguais. Essas características não devem ser vistas como femininas, mas o resultado de uma delicadeza interior, ou de um corpo treinado em representar estados de espírito através de gestos e posturas.

Por outro lado, muitas partes do corpo têm uma aparência volumosa. Em (04) Sokkonkôheisô (足跟広平相) o calcanhar é largo. Em (07) Sokufukômansô (足跃高満相): o peito do pé é cheio, como um casco de tartaruga. Em (18) Ryôekikaryûmansô (両腋下隆満相), sob a axila, o músculo está apertado e não tem concavidade, ou seja, as axilas são cheias ou inchadas. Os punhos roliços, expressados com uma única dobra, podem ser associados às mãos de crianças, característica tipicamente usada para expressar as mãos de Buda na escultura durante a primeira metade do período Heian $(794 \sim 1185)^{5}$ No pescoço normalmente aparecem três do-

5. HAYAKAWA, Monta. Explanation of the cover illustration. Japan Review. Kyôto: Bulletin of International Research Center for Japanese Studies, Nichibunken. v. 1, p. 224, 1990 e v. 7, p. 199, 1996. 
bras chamadas de sandô (三道) que representariam as três jóias do budismo: Buda, a Lei e a comunidade de monges.

Um cuidado especial foi dado à caracterização da pele. O sinal (16) Seihakuhisô (細薄皮相) se refere a uma pele muito fina e sempre imaculada, como uma pétala da flor de lótus e o (14) Konjikisô (金色相) diz que todo o corpo brilha em delicada cor de ouro. Essa pele tem o (13) Ichiichikôichimôshôsô (一一孔一毛生相) um pêlo azulado e segundo (12) Môjôkôsô (毛上向相), todo pêlo do corpo flutua para cima, como se a luz irradiasse dos poros, e essa luz é (15) Jôkôsô (丈光相), um brilho que se irradia por aproximadamente três metros em todas as direções.

A característica (10) Onzôsô (陰蔵相) é extremamente polêmica pelo sua ausência, isto é, a omissão do pênis. Em se tratando de sinais que possivelmente tiveram origem na cultura hindu que sempre idolatrou o pênis como símbolo da fertilidade e da criação, essa omissão nos dá um paradoxo para sua própria compreensão. Embora o Buda tenha sido definitivamente do sexo masculino, muitas imagens não transparecem gênero. Nas imagens humanas orientais, não fosse o bigode ou um corte de cabelo, a distinção de sexo é difícil. Algumas imagens de Buda têm finas linhas negras ao redor da boca representando a barba e o bigode, já desbotados em muitas imagens. Porém, esse bigode, que pode ser encontrado em outras imagens como a de Kannon, tida mais como uma deusa do que um deus. Precisamos compreender o que significa a representação do corpo no oriente ou o que ele personifica em meio a um reconhecimento de energias sutis que perpassam o taoísmo e ainda hoje são pesquisados e praticados como medicina alternativa. Nesse sentido, as esculturas budistas ainda guardam uma grande contribuição.

$\mathrm{Na}$ cabeça se concentra o maior número de sinais, a começar pela boca. Uma citação antiga diz que "a face de Miroku (o Buda do por vir) é a lua de outono, o globo ocular de shôren (青蓮, lótus azul) é o lago de verão, a cadeia de 40 dentes é a neve do inverno e as 32 características, as flores da primavera" (梁塵 28). Na boca há os (22) Shijûshisô (四十歯相) ou os quarenta dentes enfileirados, alvíssimos, limpos e (23) Shiseisô (歯斉相), de tamanho uniforme e sem vãos, embora se possa ver cada um. Ainda há os (24) Gehakusô (牙白相), quatro dentes caninos alvíssimos e pontudos. Sua boca tem uma saliva tão perfumada, (26) Michûtokujômisô (味中得上味相), que qualquer alimento que sorve tem sempre o melhor sabor. Curiosamente, em (27) Daizessô (大舌相) sua língua é longa e esbelta e, quando sai da boca, se estende por toda a face, até a raiz dos cabelos, mas, dentro da boca, não chega a enchê-la. De sua boca sai uma voz (28) Bonjôsô (梵声相) tão alta, bela e amável que encanta o ouvinte As bochechas são cheias, (25) Shishikyôsô (獅子頬相), "como as do leão shishi (獅子)" Apesar dos longos lóbulos das orelhas, que podem significar "aquele que tudo ouve", nenhum deles usa brincos pesados, como se deveria esperar de uma influência indiana. Os lóbulos compridos podem ser o resultado de alguma prática ascética ou uma aproximação simbólica com outros deuses, como Ganesha.

Em seus olhos, (29) Shinseigansô (真青眼相), as pupilas são grandes e da cor cinza-azulada como as pétalas da flor de lótus azul. Seus cílios, (30) Kyûganshôsô 
(牛眼正相), são longos, belos e alinhados, como os de uma vaca, e entre as sobrancelhas (miken,眉間), há um inchaço ou um pêlo branco, (32) Byakugôsô (白毫相), rodando para a direita e prolongando-se por cerca de três metros e cento e cinqüienta centímetros. Normalmente encontra-se representado como três cabelos curvos e brancos e às vezes, esses cabelos são pintados ou feitos com pedaços de quartzo. $O$ byakugô também representa um terceiro olho para "aquele que tudo vê" Esse sinal tem uma relação com o manji (Ж字), que normalmente aparece no peito das imagens de Buda e simboliza a sua grandiosa predestinação.

Infelizmente, o ocidente passou a conhecer um símbolo semelhante ao manji por meios obscuros. O termo alemão swastica vem do sânscrito svastikah, significando "ser afortunado" A raiz da palavra svasti pode ser dividida em $s u$ (sv), que significa "bom ou bem", e asti (astikah), que significa "ser ou sendo" Esse símbolo foi muito usado no budismo, no janaísmo ${ }^{6}$ e no hinduísmo. Foi originalmente usado pelos arianos, "nobres" em sânscrito, grupo que se estabeleceu no Irã e norte da Î́ndia e que acreditava ser superior às outras culturas vizinhas. No budismo, este símbolo se chama Manji ou Tokuji e significa "as dez mil virtudes do estado de buda" (butsushin), por isso man ("dez mil") e $j i$ ("letra") ou toku ("virtude") mostrados nos pelos do peito, da perna e no cabelo de Buda.

Enfim, sua cabeça possui o (31) Chôkeisô (頂譬相), um volume no topo, saliente e carnoso como um topete de galo, também chamado nikkei (肉髫). No centro do nikkei há uma jóia (nikkeishu, 肉䯽珠), que irradia a luz da sabedoria.

Essas características já eram aparentes nas imagens budistas de Gandhara ${ }^{7} \mathrm{Di}$ zem que foram originalmente evidentes no corpo de um Rei Sagrado chamado Tenrinjôô (転輪聖王) (Cakravarti) da mitologia hindu. Essa transposição de sinais deve ter sido comum devido ao caráter sincrético que o budismo assumiu desde o início de sua propagação. Na sua essência o budismo, nascido sobre as palavras de Buda, não era

6. No janaísmo, os quatro braços da cruz representam os quatro possíveis reinos de renascimento: animal ou vegetal, inferno, terra e espiritual. No hinduísmo (hinzûkyô), a suástica, com os braços voltados para a esquerda, é chamada de sauvastika ou sathio, e simboliza a noite, a magia, a pureza e a deusa $\mathrm{Kali}$, e os braços voltados para a direita, o sol, o dia, o masculino. Acredita-se que se baseia num abelo aspiral (senmô) do peito de Vishnu. In "Buddhist Corner". Disponível em www.onmarkproductions.com. Acesso em 2003; In Egawa, Kiyoshi, Aoki, Takashi, Hirata, Yoshio (comps.). Kigô-no Jiten ("Dicionário de Símbolos"). Tôkyô: Sanseidô, 1985, p. 238. "Os adeptos do bramanismo consideraram Buda como uma encarnação ilusória de Vishnu (...)". In BULFINCH, Thomas. O Livro de Ouro da Mitologia: (a idade da fábula): história de deuses e heróis. Trad. David Jardim Junior. Rio de Janeiro: Ediouro, 2002, p. 367. Enquanto desenho de várias culturas, também é usada como um tipo de crucifixo (jûjika) e a suástica nazista, hakenkreuz (hâkenkuroitsu) com os braços para a direita e o eixo inclinado em $\times$, difere do manji cujo eixo é em cruz +.

7. Hoje, noroeste do Paquistão e leste do Afeganistão entre os séculos I a.C. e 7 d.C. O papel de Gandhara na evolução das imagens budistas tem sido um ponto de desacordo considerável entre os estudiosos. Hoje parece mais claro que as escolas de Gandhara e Mathura (Uttar Pradesh, Índia) desenvolveram independentemente suas próprias características para a representação de Buda em torno do século I d.C., mas se influenciaram mutuamente. 
politeísta nem monoteísta, porém fazia renascer uma crença milenar em milhares de budas que já teriam vindo a esse mundo e os que estão por vir. Só os sábios, como o mencionado Asita, em conhecimentos ocultos sabiam quem eram budas, de onde vinham e como distingui-los pelos ensinamentos e pelas características físicas. Também é conveniente que tais características, ou ao menos uma delas, estivessem no corpo dos soberanos de várias culturas, ou ao contrário.

A proeminência no topo da cabeça (nikkei ou ushnisha) sugere uma superinteligência ou um desenvolvimento sobre-humano (um ser humano completamente maduro) que só o Butchô-son ${ }^{8}$ pode possuir e os homens não iluminados, mesmo que divinamente inspirados, não podem penetrar. No budismo esotérico, esse nikkei é chamado butchô (仏頂), que por si mesmo é considerado Buda. Porém, assim como o cabelo em forma de caracóis pode ter sido uma transformação dos cabelos encaracolados, como se discutirá em seguida, essa protuberância pode resultar de transformação de um simples coque de cabelo de algum penteado usado pela nobreza, detalhe que pode ser encontrado em muitas estátuas. Esse nikkei também colabora na imponência da imagem.

Seguindo a lógica dos pelos azulados, naturalmente o cabelo de Buda era azul, ou melhor, de caracóis azuis. Essa cor de cabelo é mais facilmente vista nas pinturas coloridas. Sabe-se que Buda raspou a sua cabeça quando decidiu ser um monge, mas não se sabe se ele continuou essa prática. De fato, os monges atuais sempre raspam a cabeça em sinal de desapego. Então, a pergunta que sempre se faz é "o que seriam aqueles caracóis (rahotsu, 螺髪) sobre sua cabeça?" Dentre as várias hipóteses lendárias sobre esse tipo de cabelo, há as que dizem que teria sido uma corda enrolada sobre a cabeça raspada ou que vários caracóis teriam coberto a cabeça de Buda para protegêlo do sol enquanto meditava. Se for cabelo, é um cabelo muito enrolado, que, com o tempo foi se estilizando numa forma fixa de representação abstrata. Hoje temos provas arqueológicas de que as imagens humanas de Gandhara normalmente tinham cabelos encaracolados como os das estátuas gregas de deuses e sábios. Cabelos frisados são comuns em várias culturas: grega, romana, mesopotâmia. Também são encontrados na arte etrusca. Enfim, não temos base para supor que tenha sido algum tipo de touca. Desse cabelo encaracolado, makige (巻き毛), como o dos budas de Gandhara, diz-se, na escultura, "plantar rarotsu" (uetsuke, 植付け) o colocar pedacinhos de madeira e "cortar rarotsu" (kitsuke, 切付 if), o entalhar. De qualquer modo, o arranjo do cabelo sempre foi uma preocupação na estratificação social do leste asiático, sobretudo no Japão. Na cabeça de algumas outras divindades budistas podemos encontrar o cabelo tipo mage (髹), o atado de cabelo no alto da cabeça, hôkei (宝髪). Há uma estátua do Buda chamado Monju com cinco desses "nós" na cabeça.

8. Também conhecida como Ichijikinrin Nyorai. É tida como a divinização da parte superior da cabeça de Buda. É a representação do estado de buda quando alcançou a concentração da mente e entrou em meditação, e por isso, naquela hora houve uma grande quantidade de energia na cabeça. Várias imagens a representam como Os Cinco Butchô-son, Os Oitos Butchô-son e Os Dez Butchô-son. 
Uma quantidade tão grande de características corporais nos dá a impressão de um estudo anatômico de um ser que, por esse ângulo, deixa de ser sobrenatural em algum momento histórico remotíssimo. Ou tais características realmente existiram ou a descrição artística minuciosa deu vida e realismo às imagens, hoje sobrenaturais, de Buda.

Vê-se que a explicação de muitas características requer um esforço de interpretação multidisciplinar. Podem ser o resultado de lendas próprias ou não ao budismo, de interesses sociais por parte de soberanos que viram no budismo um meio de controle social, do sincretismo budista com as outras religiões e filosofias orientais e empréstimos artísticos de muitas outras imagens e culturas que se perderam no tempo. $\mathrm{O}$ que torna a arte budista especial não é só sua riqueza plástica, mas também é essa capacidade de preservar uma grande quantidade de simbologias mais remotas que $o$ próprio Buda e ainda assim poderem ser discutidas de vários ângulos.

\section{Bibliografia}

"Buddhist Corner" Disponivel em www.onmarkproductions.com. Acesso em 2003. A DICTIONARY of Japanese Art Terms. Tôkyô Bijutsu, 1990.

BULFINCH, Thomas. O Livro de Ouro da Mitologia: (a idade da fábula): história de deuses e heróis. Trad. David Jardim Junior. Rio de Janeiro: Ediouro, 2002.

EGAWA, Kiyoshi, AOKI, Takashi, HIRATA, Yoshio (comps.). Kigô-no Jiten ("Dicionário de Símbolos"). Tôkyô: Sanseidô, 1985.

HAYAKAWA, Monta. Explanation of the cover illustration. Japan Review. Kyôto: Bulletin of International Research Center for Japanese Studies, Nichibunken. v. 1, p. 224, 1990 e v. 7, p. 199, 1996.

JAPANESE-English Buddhist Dictionary ("Dicionário de Termos Budista em Japonês-Inglês"). Tôkyô: Daitô Shuppansha, 1965.

JAPANESE-English Buddhist Dictionary. Tôkyô: Daitô Shuppansha, 1965,

SAWA, Ryûten (comp.). Butsuzôzuten. Tôkyô: Yoshikawa Kôbunkan, 1972. 